Herschel, Sir JoHn (1849) Quoted from Applied Regression Analysis (2nd edition). N.R. Draper \& H. Smith. Chichester: Wiley, 1981.

TUKEY, J.W. (1977) Exploratory Data Analysis. Addison Wesley.

D. H. MYERS, Shelton Hospital, Bicton Heath, Shrewsbury SY3 8DN

\section{Dosage information in the British National Formulary}

Sir: We write to add our wholehearted support to Ann Barker for raising various concerns about dosage information contained in the British National Formulary (BNF) and how they have come to be used. (Psychiatric Bulletin, 1993, 17, 557). For some time now, in relation to the use of lithium medication we have been airing similar concerns about BNF and MIMS (Monthly Index of Medical Specialities). Both publications set out their aims and scope in their preface, for rapid reference and for use as a prescribing guide. Nonetheless, the publications seem to acquire a legal standing as, for example, "BNF maximum". The contents should be accurate and up to date so as to enjoy professional confidence and credibility. Otherwise how else could one reconcile major differences between BNF and MIMS as in the maximum suggested dose of injection Depixol where BNF suggests a maximum of $400 \mathrm{mg}$ weekly and MIMS "up to $300 \mathrm{mg}$ every 2 weeks".

We are pleased that a Royal College Consensus Group is looking into these issues. The group may wish to examine the accuracy and current validity of relevant entries in BNF and MIMS so that medical practitioners are better informed and their patients better served let alone legal implications. Regarding lithium medication, the problem is with dose, side effects, toxicity and contra-indications, for which the information is outdated and sometimes conflicting. The Third British Lithium Congress held in Wolverhampton in September 1992 established a working group to produce a consensus report on proposed guidelines for good clinical practice to deal with the problems out of date information in the BNF and MIMS. (Lithium Prophylaxts: Proposed Guidelines for Good Clinical Practice. (Report of a working party established by the Third British Lithium Congress, Wolverhampton 6-10 September 1992). N.J. Birch (Chairman of the Working Party), P. Grof, R.P. Hullin, R.F. Kehoe, M. Schou and D.P. Srinivasan. Lithium, 4, November 1993).

D.P. SRINIVASAN, Garlands Hospital, Carlisle CA1 3SX; and N.J. BIRCH, Blomedical Research Laboratory, School of Health Sclences, University of Wolverhampton, Wolverhampton WV1 1DJ

\section{GPs' views of psychotherapy services}

Sir: I was interested to read the paper by Morton \& Staines on 'GP use of psychotherapy services' (Psychiatric Bulletin, 17, 526-527). I agree that little is known about how GPs view psychotherapy services, and heartened to see that, despite the ideological and organisational changes imposed on the NHS of late, the results indicate that GPs continue to value NHS psychotherapy services. My own study of GPs' views of psychotherapy services in Central Manchester in 1984-85 demonstrated a high degree of GP support for the services (95\%), and many wanted more contact with the services and opportunities for further training and supervision for themselves (Reilly, 1987). There was a clear need for dialogue between GPs and psychotherapists then, and no doubt the need is greater now, with general practice fund-holding and the need of provider units to attract referrals.

In York we are currently conducting a simple audit of GPs views and utilisation of the local NHS counselling and psychotherapy service. No doubt psychotherapy units around the country have or will be planning to do the same. It would be interesting to compare notes.

RELLY, S.P. (1987) A psychotherapy service: how general practitioners see it. Bulletin of the Royal College of Psychiatrists, 11, 191-192.

STEPHEN REILLY, Bootham Park Hospital, York YO3 7BY

\section{'Bulletin' readership survey}

Sir: Tom Fahy should be congratulated on his excellent survey and his courage in publicly challenging the editorial policy of the widely loved and respected Bulletin (Psychiatric Bulletin, $1993,17,473-476)$. His survey suggests an easy method of lowering the increasing rate of rejection of articles submitted to the Bulletin. Stop publishing the interviews and use the space to publish what the punters want and read. His survey showed less than $20 \%$ of readers usually always read interviews, but almost $50 \%$ usually or always read Audit in Practice. In the same edition of the Bulletin an interview with Professor Leighton was eight pages long while my paper on audit was only two pages (Hodgson et al, 478479). Excluding the intervlew would have provided four time as much space for similar audit articles of the same length, or the opportunity for $96 \%$ of the readership to read original papers or research reports.

OLA JUNAID, Nottingham Healthcare Unit, Mapperley Hospttal, Nottingham NG3 6AA 
This survey was commissioned by the editors and was not intended to challenge editorial policy but to seek readers' views.

The editors believe that the interviews published in the Psychiatric Bulletin have been of much interest and value. A selection have recently been published in Talking about Psychiatry in which eloquent justification is made in the Preface as providing a unique perspective on British psychiatry. However, and this may relate to Dr Junaid's point in part, interviews have been traditionally conducted with eminent psychiatrists in retirement but are now to include colleagues who remain active and who have also distinguished themselves in other spheres as well as psychiatry.

\section{EDITOR}

\section{Pharmacotherapy and wilful patient deception}

Sir: The article by Dr Clarke (Psychiatric Bulletin 1993, 17, 469-470) made interesting reading. The possibilities of adverse drug reactions in psychiatric patients are very real and can be overlooked. One factor not mentioned was the possibility of deliberate patient deception and, although infrequent, we feel it bears mention. Recently we encountered two patients with atypical symptoms related to this area whose behavlour proved hazardous to themselves and the treatment process.

One 30-year-old woman presented with ataxia and sedation while receiving treatment with antidepressants, and subsequently responded well to treatment as an in-patient. She later admitted using her child's methylphenidate and carbamazepine along with over-the-counter preparations. A second woman presented with bizarre neurological complaints during treatment with a tricyclic agent; the symptoms of meningism and headache persisted after the tricyclic was stopped. Later, she revealed that she was receiving oral retinoid therapy for acne but did not mention this lest the treatment was discontinued. Her subsequent response to treatment was good.

Patients may therefore wilfully mislead their psychiatrists on occasion especially regarding medication. The quality of the information we recelve depends on a number of factors, and the use of over-the-counter preparations, herbal remedies and medications prescribed for others may jeopardise the patient and the treatment process. The fault may lie with the patient rather than the specialist who adheres too rigidly to his or her own area. The information may simply not be forthcoming despite exhaustive enquiry.

ALAN BYRNE, and GARY HNATKO, University of Alberta, Edmonton, Canada

\section{Sexist case-notes can be useful}

Sir: How sad that M. Phillips (Psychiatric Bulletin, $1993,17,432$ ) has revealed to the world the 'sexist' nature of medical record files kept at the Maudsley Hospital (women, buff colour; men, green). The reason for the differential colour coding has nothing to do with ease of retrieval etc (though this is commonly used as the pretext). It is, in reality, a subtle test of common sense for new Maudsley recruits. Common sense is a notoriously difficult ability to assess at interview and has no correlation with number of publications (O'Brien et al, unpublished observations on a frighteningly large and ever growing personal series). A registrar's 'time to realisation' that males and females have different coloured files is a reliable and valid measure which, in addition. never ceases to amuse those who have already attained this milestone. Although I do not have detailed figures to hand, I feel that the 18 months described by Dr Phillips is perilously close to being outside 2 standard deviations of the mean. However, Dr Phillips can be reassured in the knowledge that several leading academics (they know who they are) have failed to reach this goal without assistance from others.

On a more serious note, colour coded casenotes can be an invaluable part of the psychiatric examination. I became aware of such benefits when working in a clinic performing assessments on potential candidates for gender reassignment surgery. If potential male-to-female transsexuals appeared carrying buff (female) files after registering, they had demonstrated their ability to live successfully as the opposite sex, by fooling the reception staff. But if they falled to demonstrate 'O'Brien's sign', and walked in with a green file, then it was clear more work needed to be done before surgery could be considered. This simple measure, of which patients (like Dr Phillips) were blissfully unaware, saved hours of informant history gathering. Despite my expertences in the gender identity clinic, I remain convinced that important differences do exist between men and women. I would suggest that 'sexdst' colour coding of notes is not only a reflection of this but can aid in psychiatric assessment.

John T. O'Brien, Untuerstty of Melbourne, Clinical Sclences Butlding, Mont Park Hospttal, Rosanna, Victoria 3084, Australia

\section{Day care in old age psychiatry}

Sir: Dr Ball (Psychiatric Bulletin, 1993, 17, 427428) attempts a critique of day care in old age psychiatry. As in all NHS services, historical factors determine the development of services. The 'Worthing experiment' (Carse et al., 1958) is perhaps the original demonstration of active treatment in a day hospital to prevent admission 